\title{
Regulation of gene expression by photosynthetic signals triggered through modified $\mathrm{CO}_{2}$ availability Dennis Wormuth ${ }^{1}$, Margarete Baier ${ }^{1}$, Andrea Kandlbinder$^{1}$, Renate Scheibe ${ }^{2}$, Wolfram Hartung ${ }^{3}$ and Karl-Josef Dietz*1
}

\author{
Address: ${ }^{1}$ Biochemistry and Physiology of Plants, Bielefeld University - W5, 33501 Bielefeld, Germany, ${ }^{2}$ Plant Physiology, University of \\ Osnabrück, FB 5, 49069 Osnabrück, Germany and ${ }^{3}$ Molecular Plant Physiology and Biophysics, Julius von Sachs-Institut für Biowissenschaften, \\ 97082 Würzburg, Germany \\ Email: Dennis Wormuth - dennis.wormuth@uni-bielefeld.de; Margarete Baier - margarete.baier@uni-bielefeld.de; \\ Andrea Kandlbinder - andrea.kandlbinder@uni-bielefeld.de; Renate Scheibe - Renate.Scheibe@Biologie.Uni-Osnabrueck.DE; \\ Wolfram Hartung - hartung@botanik.uni-wuerzburg.de; Karl-Josef Dietz* - karl-josef.dietz@uni-bielefeld.de \\ * Corresponding author
}

Published: 17 August 2006

BMC Plant Biology 2006, 6:15 doi:10.1 I86/1471-2229-6-15
Received: 28 April 2006

Accepted: 17 August 2006

This article is available from: http://www.biomedcentral.com/147I-2229/6/15

(c) 2006 Wormuth et al; licensee BioMed Central Ltd.

This is an Open Access article distributed under the terms of the Creative Commons Attribution License (http://creativecommons.org/licenses/by/2.0), which permits unrestricted use, distribution, and reproduction in any medium, provided the original work is properly cited.

\begin{abstract}
Background: To coordinate metabolite fluxes and energy availability, plants adjust metabolism and gene expression to environmental changes through employment of interacting signalling pathways.

Results: Comparing the response of Arabidopsis wild-type plants with that of the mutants adgl, pgrl and vtcl upon altered $\mathrm{CO}_{2}$-availability, the regulatory role of the cellular energy status, photosynthetic electron transport, the redox state and concentration of ascorbate and glutathione and the assimilatory force was analyzed in relation to the transcript abundance of stress-responsive nuclear encoded genes and $\mathrm{psaA}$ and $\mathrm{psbA}$ encoding the reaction centre proteins of photosystem I and II, respectively. Transcript abundance of Bap I, StpI, psaA and psaB was coupled with seven metabolic parameters. Especially for $\mathrm{psa} A$ and $\mathrm{psaB}$, the complex analysis demonstrated that the assumed PQ-dependent redox control is subordinate to signals linked to the relative availability of 3-PGA and DHAP, which define the assimilatory force. For the transcripts of sAPx and Csd2 high correlations with the calculated redox state of NADPH were observed in pgrl, but not in wildtype, suggesting that in wild-type plants signals depending on thylakoid acidification overlay a predominant redox-signal. Strongest correlation with the redox state of ascorbate was observed for 2CPA, whose transcript abundance regulation however was almost insensitive to the ascorbate content demonstrating dominance of redox regulation over metabolite sensing.
\end{abstract}

Conclusion: In the mutants, signalling pathways are partially uncoupled, demonstrating dominance of metabolic control of photoreaction centre expression over sensing the redox state of the PQpool. The balance between the cellular redox poise and the energy signature regulates SAPx and Csd2 transcript abundance, while 2CPA expression is primarily redox-controlled.

\section{Background}

Photosynthesis provides plant cells with assimilates, reducing power and ATP. To coordinate their supply and demand, plants respond to environmental changes on 
time scales ranging from milliseconds to days. In addition to biochemical regulation of enzyme activities, control of gene expression is essential for long-term adjustment of metabolic capacities. However, the photosynthetic electron transport chain and chloroplast metabolism have evolved as patchworks composed of nuclear and plastidencoded proteins and depend on coordination of gene expression between compartments. In recent years, physiological and mutant approaches addressed the regulatory function of metabolite signals [1], energy status [2] and chloroplast redox signals [3]. For example, carbohydrates induce expression of genes involved in starch biosynthesis and suppress those involved in starch degradation and carbon assimilation [4]. In parallel, in the plastids, expression of e.g. core subunits of the photoreaction centres and the large subunit of RuBisCO are suppressed either by coregulation of transcription or epistatically. Photosynthates further inhibit the Calvin-Cycle biochemically [5] and decrease the consumption of NADPH and ATP, which results in an increased reduction state of the NAD(P)-system and a higher phosphorylation state of adenylates $[6,7]$. The lack of NADP+ as electron acceptor and the generation of a high trans-thylakoid $\Delta \mathrm{pH}$ by decreased photophosphorylation reduce the carriers of intersystem electron transport, like plastoquinone pool (PQ), and stimulate ROS formation [8-10]. $\mathrm{PQH}_{2}$ and ROS are redox signals controlling nuclear and plastid gene expression $[11,12]$. The combination of decreased NADP ${ }^{+}$regeneration and high thylakoid acidification promotes the violaxanthin cycle, which can support biosynthesis of the plant hormone abscisic acid [13] if ascorbate availability is limiting [14].

The plant signalling networks evolved in the context of a strong interference of photosynthates and redox and energy signals. Therefore, in $w t$ distinction of particular signals is often difficult. Here, for differentiation, gene expression regulation was analyzed in $w t$, in the thylakoid acidification mutant pgr1 [15], in the starch-biosynthetic mutant adg1 [16] and in the ascorbate-deficient mutant $v t c 1$ [17] in response to the $\mathrm{CO}_{2}$ availability.

pgr1 is mutated in the Rieske subunit of the cytochrome $\mathrm{b}_{6} \mathrm{f}$ complex (PetC; [15]) that is involved in electron and proton transfer processes between photosystem II and I as a plastohydroquinol-plastocyanin reductase. Due to a shift in the $\mathrm{pK}$ or the redox potential of the Rieske protein, thylakoid lumen acidification is restricted in the mutant to pH 6 even in high light [18]. Consequently, the mutant has altered capacities for ADP photophosphorylation [19] and PsbS protonation [20], and may be limited in violaxanthin de-epoxidation [21] and cyclic electron transport [22]. In pgr1, high light intensities increase the electron pressure to the PQ pool and release the electron pressure downstream of the $\mathrm{cytb}_{6} \mathrm{f}$ complex. Pgr1 was selected in this communication for its limitation in membrane energization and photosynthetic electron transport.

adg1 carries a mutation in the small subunit of ADP-glucose pyrophosphorylase [16]. It was selected for its altered carbohydrate metabolism. In contrast to pgr1, in adg1 photosynthetic electron transport is affected only indirectly by carbohydrate-induced feedback inhibition [23].

The third selected mutant, $v t c 1$, carries a point mutation in GDP-mannose pyrophosphorylase [17], which catalyzes precursor formation in the biosynthesis of the low-molecular weight antioxidant ascorbate. vtc1 was included in this analysis to investigate the importance of ascorbate availability and ascorbate-related redox processes on nuclear and plastid gene expression.

Arabidopsis $w t$ and the mutants were compared under conditions of limiting, ambient and saturating $\mathrm{CO}_{2}$ concentrations. Below the $\mathrm{CO}_{2}$ compensation point, RuBisCO preferentially catalyzes oxygenation of ribulose1,5-bisphosphate and activates photorespiration, which triggers an extra demand for ATP. Per reaction cycle, chloroplastic NADPH consumption is low under photorespiratory as compared to assimilatory conditions. In addition, at very low $\mathrm{CO}_{2}$ concentrations, depletion of the carbohydrate pool may suppress photorespiration and limit photoprotection. Concomitantly, the ROS load increases due to high peroxisomal $\mathrm{H}_{2} \mathrm{O}_{2}$ production and chloroplast superoxide generation. At ambient conditions, $30-40 \%$ of the carbon fluxes diverts to photorespiratory $\mathrm{CO}_{2}$ release, while saturating $\mathrm{CO}_{2}$ suppresses photorespiration and the requirement for ATP to NADPH approaches a ratio of 3:2. In parallel, energization and reduction state of the cells are decreased [24].

The hypothesis of the work was that the combination of working with defined mutants and altering $\mathrm{CO}_{2}$ availability for modulation of photosynthesis allows addressing the question of how selected nuclear and plastidic genes are regulated in Arabidopsis in response to redox, metabolite and energy signals.

\section{Results}

The work aimed at differentiating signals involved in the control of gene expression. To this end Arabidopsis $w t$ and mutants defective in chloroplast starch biosynthesis (adg1; [16]), thylakoid acidification (pgr1; [15]) and the biosynthesis of the major low-molecular-weight antioxidant ascorbate $(v t c 1$; [17]) were compared in relation to their metabolite patterns, photosynthetic performance and transcript amount regulation. Following growth at ambient conditions, the $\mathrm{CO}_{2}$ availability was decreased for $6 \mathrm{~h}$ to levels below the $\mathrm{CO}_{2}$ compensation point or increased to saturation of RuBisCO to establish contrast- 
ing conditions for photosynthesis with high and low acceptor availability and concomitant high and low reduction pressure.

\section{Metabolic regulation The energy status}

In $w t$ during the $6 \mathrm{~h}$ fumigation period the ADP content increased 1.5-2-fold irrespective of the treatment (Table 1). In parallel, the ATP accumulated only in $0 \mathrm{ppm} \mathrm{CO}_{2}$, but decreased in 350 and 2000 ppm $\mathrm{CO}_{2}$. The ATP/ADP ratio was nearly unchanged around 6 in 0 ppm, but decreased to 2.2 and 1.8, respectively, in 350 and 2000 ppm $\mathrm{CO}_{2}$ (Table 1). Mutant metabolism resulted in specific modifications of the $w t$-pattern:

In $a d g 1$, ATP and ADP accumulated 2.2- and 5.5-fold in 0 ppm $\mathrm{CO}_{2}$ and 1.3- and 1.9-fold in 350 ppm $\mathrm{CO}_{2}$ indicating an increase in the total adenylate concentration, but a decrease in the ATP/ADP ratio. In $2000 \mathrm{ppm} \mathrm{CO}_{2}$ the ATP content increased insignificantly, while the ADP content decreased resulting in an ATP/ADP ratio similar to the initial values obtained before the treatment (Table 1).

The ATP content of $v t c 1$ slightly but steadily decreased with increasing $\mathrm{CO}_{2}$ availability, while the ADP content increased from the lowest levels observed prior to the fumigation experiment 6.2-fold in $0 \mathrm{ppm} \mathrm{CO}_{2}, 2$.8-fold in 350 ppm $\mathrm{CO}_{2}$ and 3.3-fold in $2000 \mathrm{ppm} \mathrm{CO}_{2}$ (Table 1). The high ATP and especially the low ADP contents after 6 $h$ resulted in a strong decrease in the ATP/ADP-ratio from 9.8 to around 2 (Table 1 ).

pgr1 is limited in thylakoid acidification [18]. Like in vtc1, the ATP/ADP ratio decreased to values around two during the experiment independent of the $\mathrm{CO}_{2}$ concentration applied (Table 1). However, the relative decrease was much less in pgr1 due to an already much lower initial $\mathrm{ATP} / \mathrm{ADP}$ ratio (vtc1: 9.8 ; pgr1: 2.9 ). In addition to the generally low ATP/ADP ratio, the total adenylate concentration was also low in pgr1 suggesting coupling between adenylate biosynthesis and ADP-phosphorylation efficiency. The ADP contents were similar to that in $w t$ and did not increase in 0 ppm like in $v t c 1$ and $a d g 1$ (Table 1), while the ATP content slightly decreased demonstrating a mutation-specific difference in regulation of the adenylate concentration in parallel to the ATP/ADP ratio (Table 1).

\section{Assimilatory force and the reduction state of the NADP system}

The assimilatory force $\mathrm{F}_{\mathrm{A}}$, i.e. the product of the phosphorylation potential $[\mathrm{ATP}] /[\mathrm{ADP}]\left[\mathrm{P}_{\mathrm{i}}\right]$ and the ratio of $[\mathrm{NADPH}] /\left[\mathrm{NADP}^{+}\right]$, was calculated from the DHAP/3PGA ratio (Table 1) as introduced in [24]. $\mathrm{F}_{\mathrm{A}}$ indicates the energization of metabolism by photosynthetic light reactions as compared to the consumptive demand. The rela- tionship was originally defined for chloroplasts. Due to energy and metabolite coupling it also tentatively describes the energy status of leaves [25]. $\mathrm{F}_{\mathrm{A}}$ was increased in $w t$ and all mutants during $6 \mathrm{~h}$ in $\mathrm{CO}_{2}$-free air compared to the values at onset of fumigation (wt: 180\%; adg1: 352\%; pgr1 180\%; vtc1: 347\%) (Table 1) indicating a high reduction state of the NADP-system ( $w t$ : 148\%; adg1: 385\%; pgr1 194\%;vtc1: 326\% increase compared to the onset of illumination) (Table 1). At high $\mathrm{CO}_{2}$, the $[\mathrm{NADPH}] /\left[\mathrm{NADP}^{+}\right]_{\text {calc }}$ ratios of the mutants were little increased in $w t(175 \%)$, adg1 (155\%) and pgr1 (123\%), but elevated in vtc1 (366\%) compared to the values at onset of fumigation (Table 1 ). The calculated reduction states of NADP at high $\mathrm{CO}_{2}$ were increased in $w t(241 \%)$, adg1 (152\%) and pgr1 (153\%), but hardly changed in vtc1 $(108 \%)$ relative to ambient conditions (Table 1$)$.

The strong decline in the 3-PGA content in $\mathrm{CO}_{2}$-free air indicated an increased assimilatory force in low $\mathrm{CO}_{2}(w t$ : 685\%; adg1: 511\%; pgr1: 301\%; vtc1: 326\% relative to ambient air). 3-PGA contents slightly increased in 350 ppm $\mathrm{CO}_{2}$ during the $6 \mathrm{~h}$ of treatment, remained unchanged in $w t$ in 2000 ppm $\mathrm{CO}_{2}$ and decreased in the mutants.

\section{Antioxidant protection}

Antioxidant enzymes and low molecular weight redox metabolites constitute the antioxidant defence system of the plants. Modifications of antioxidant enzyme activities often reflect general changes in the redox status and in ROS generation of the tissue, or compensatory responses to specific redox changes [26].

\section{Ascorbate contents and redox states}

At the beginning of the fumigation period, the ascorbate content was lowest in $v t c 1$ with $1.44 \pm 0.31 \mu \mathrm{mol} \mathrm{Asc} / \mathrm{g}$ FW reflecting the mutational defect in ascorbate biosynthesis [17] (Fig. 1). The highest ascorbate levels were observed in $w t$, and intermediate contents in adg1 and pgr1. In $w t$ the ascorbate content increased approximately 1.3-fold in ambient air, but hardly changed in low and high $\mathrm{CO}_{2}$. In adg1, starting with a lower content than $w t$, ascorbate levels increased to high values at $350 \mathrm{ppm}$ and were unchanged in 0 and $2000 \mathrm{ppm} \mathrm{CO}_{2}$. In $v t c 1$, with its low ascorbate contents due to the mutation in one of the main ascorbate biosynthetic enzymes, ascorbate increased 1.3-fold in $\mathrm{CO}_{2}$-free air and 2.1- and 1.8-fold in 350 and $2000 \mathrm{ppm} \mathrm{CO}_{2}$. It maximally reached $50 \%$ of the $w t$ level in $350 \mathrm{ppm} \mathrm{CO}_{2}$. In pgr1, the ascorbate content increased to $4.5 \pm 0.75 \mu \mathrm{mol} \mathrm{Asc} / \mathrm{g} \mathrm{FW}$ in $0 \mathrm{ppm}$ and to similar levels around $6 \mu \mathrm{mol} \mathrm{Asc} / \mathrm{g} \mathrm{FW}$ in $350 \mathrm{ppm}$ and $2000 \mathrm{ppm} \mathrm{CO}_{2}$. The $\mathrm{CO}_{2}$ availability affected the redox state of ascorbate to a minor extent. From an almost fully reduced level at the beginning of the fumigation period, the mean values after $6 \mathrm{~h}$ fumigation indicate slightly higher oxidation lev- 



vtcl under different $\mathrm{CO}_{2}$ regimes $\left(0 \mathrm{ppm}, 350 \mathrm{ppm}\right.$ and $\left.2000 \mathrm{ppm} \mathrm{CO}_{2}\right)$.

\begin{tabular}{|c|c|c|c|c|c|c|c|c|c|c|}
\hline \multirow[b]{2}{*}{ wt } & \multirow[b]{2}{*}{ ATP } & \multirow[b]{2}{*}[\mathrm{nmol}/\mathrm{g}\mathrm{FW}]{} & \multicolumn{2}{|l|}{ Start } & \multicolumn{2}{|c|}{$0 \mathrm{ppm} \mathrm{CO}{ }_{2}$} & \multicolumn{2}{|c|}{$350 \mathrm{ppm} \mathrm{CO}$} & \multicolumn{2}{|c|}{$2000 \mathrm{ppm} \mathrm{CO}$} \\
\hline & & & $97.6 \pm 15.6$ & c & $172.9 \pm 31.9$ & $\mathrm{a}$ & $79.1 \pm 14.7$ & eg & $60.9 \pm 9.5$ & efg \\
\hline & ADP & & $17.5 \pm 2.8$ & c & $29.7 \pm 4.5$ & b & $36.2 \pm 10.4$ & $\mathrm{~b}$ & $33.1 \pm 23.3$ & bc \\
\hline & 3PGA & & $294.0 \pm 149.2$ & $a b c$ & $117.0 \pm 73.3$ & c & $404.1 \pm 44.4$ & b & $301.0 \pm 126.4$ & $b c$ \\
\hline & DHAP & & $100.0 \pm 10.4$ & $a b c$ & $71.7 \pm 40.2$ & c & $36.1 \pm 15.3$ & $b$ & $76.4 \pm 49.5$ & $\mathrm{bc}$ \\
\hline & ATP/ADP & & 5.6 & & 5.8 & & 2.2 & & 1.8 & \\
\hline & {$\left[\mathrm{NADPH} / \mathrm{NADP}^{+}\right]_{\mathrm{calc}}$} & & 23.0 & & 34.0 & & 16.7 & & 40.3 & \\
\hline & Assimilatory Force & & 333.0 & & 600.4 & & 87.6 & & 248.7 & \\
\hline \multirow[t]{7}{*}{ adg I } & ATP & {$[\mathrm{nmol} / \mathrm{g} \mathrm{FW}]$} & $68.2 \pm 8.7$ & e & $149.6 \pm 25.6$ & $a b c$ & $88.8 \pm 5.1$ & c & $77.9 \pm 13.4$ & ed \\
\hline & ADP & & $20.6 \pm 10.1$ & bc & $113.6 \pm 25.0$ & $\mathrm{a}$ & $39.7 \pm 24.5$ & bc & $18.8 \pm 4.2$ & $\mathrm{bc}$ \\
\hline & $3 P G A$ & & $341.2 \pm 123.3$ & $b$ & $113.7 \pm 37.5$ & c & $487.6 \pm 81.3$ & $a b$ & $256.4 \pm 123.3$ & $\mathrm{bc}$ \\
\hline & DHAP & & $46.0 \pm 15.0$ & $b$ & $54.0 \pm 38.8$ & c & $45.3 \pm 24.2$ & $a b$ & $75.8 \pm 96.2$ & bc \\
\hline & ATP/ADP & & 3.3 & & 1.3 & & 2.2 & & 4.2 & \\
\hline & {$\left[\mathrm{NADPH} / \mathrm{NADP}^{+}\right]_{\mathrm{calc}}$} & & 16.6 & & 63.9 & & 16.9 & & 25.8 & \\
\hline & Assimilatory Force & & 132.1 & & 456.7 & & 91.0 & & 289.5 & \\
\hline \multirow[t]{7}{*}{ pgrl } & ATP & {$[\mathrm{nmol} / \mathrm{g} \mathrm{FW}]$} & $71.1 \pm 12.4$ & ef & $57.5 \pm 9.3$ & ef & $84.6 \pm 4.4$ & $d$ & $53.4 \pm 9.3$ & $f$ \\
\hline & ADP & & $24.5 \pm 10.3$ & bc & $29.5 \pm 7.4$ & $b$ & $44.3 \pm 12.7$ & $b$ & $24.2 \pm 11.0$ & $c$ \\
\hline & 3PGA & & $511.9 \pm 142.0$ & $a b$ & $137.2 \pm 49.2$ & c & $522.5 \pm 14.3$ & $\mathrm{a}$ & $249.9 \pm 96.8$ & $\mathrm{bc}$ \\
\hline & DHAP & & $90.0 \pm 13.0$ & $a b$ & $43.5 \pm 27.3$ & c & $46.1 \pm 11.8$ & $\mathrm{a}$ & $44.1 \pm 13.4$ & bc \\
\hline & ATP/ADP & & 2.9 & & 1.9 & & 1.9 & & 2.2 & \\
\hline & {$\left[\mathrm{NADPH} / \mathrm{NADP}^{+}\right]_{\mathrm{calc}}$} & & 22.9 & & 44.4 & & 18.4 & & 28.2 & \\
\hline & Assimilatory Force & & 172.3 & & 311.0 & & 86.5 & & 173.0 & \\
\hline \multirow[t]{7}{*}{ vtcl } & ATP & {$[\mathrm{nmol} / \mathrm{g} \mathrm{FW}]$} & $116.0 \pm 21.6$ & $\mathrm{bc}$ & $101.6 \pm 38.0$ & bcdg & $96.8 \pm 9.8$ & $\mathrm{cdg}$ & $79.9 \pm 12.7$ & ceg \\
\hline & ADP & & $11.9 \pm 4.5$ & bc & $74.8 \pm 10.3$ & $a^{\circ}$ & $33.1 \pm 14.1$ & $\mathrm{~b}$ & $39.2 \pm 22.0$ & bc \\
\hline & 3PGA & & $355.1 \pm 35.9$ & $a b$ & $144.3 \pm 96.5$ & c & $392.2 \pm 130.9$ & b & $288.3 \pm 61.1$ & bc \\
\hline & DHAP & & $40.0 \pm 15.0$ & $a b$ & $56.4 \pm 23.2$ & c & $50.9 \pm 24.3$ & b & $29.0 \pm 9.8$ & $\mathrm{bc}$ \\
\hline & ATP/ADP & & 9.8 & & 1.4 & & 2.9 & & 2.0 & \\
\hline & {$\left[\mathrm{NADPH} / \mathrm{NADP}^{+}\right]_{\text {calc }}$} & & 5.3 & & 58.5 & & 17.9 & & 19.4 & \\
\hline & Assimilatory Force & & 110.4 & & 383.4 & & 127.3 & & 98.5 & \\
\hline
\end{tabular}

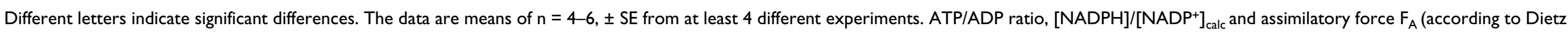
\& Heber 1989). These derived parameters were calculated from the primary data above. 

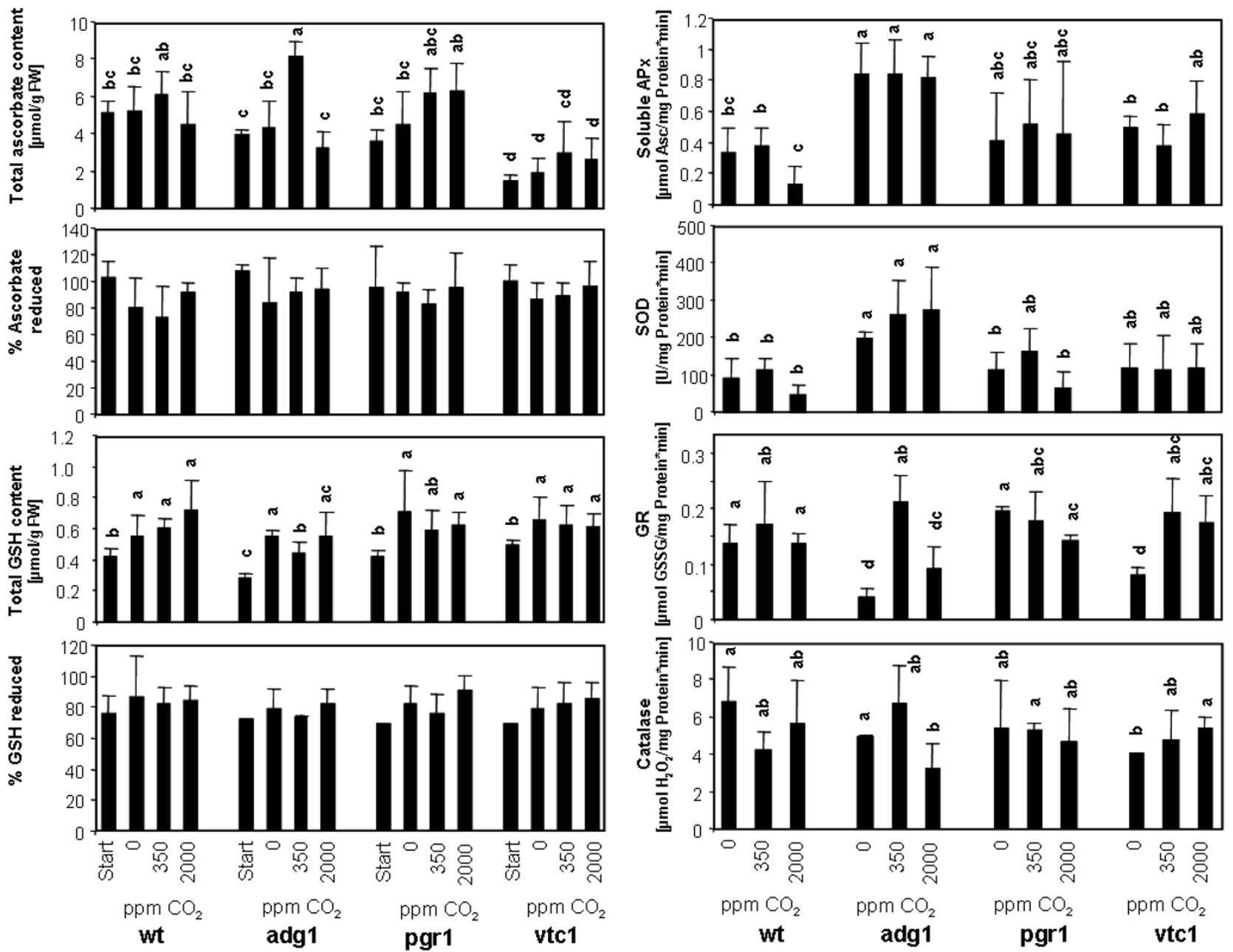

Figure I

Redox stabilization and antioxidant defense in response to differing $\mathrm{CO}_{2}$ availability: Content of total antioxidant amount and reduction status (ascorbate and glutathione) and activities of selected antioxidative enzymes: total soluble ascorbate peroxidases (APx), total soluble superoxide dismutases (SOD), glutathione reductase (GR) and catalases (CAT) in wt, adgl, pgrl and vtcl under different $\mathrm{CO}_{2}$ regimes $\left(0 \mathrm{ppm}, 350 \mathrm{ppm}\right.$ and 2000 ppm $\left.\mathrm{CO}_{2}\right)$ measured in aqueous extracts. The data are means of $n=4-6, \pm$ SE from at least 4 different experiments.

els $(72-91 \%)$ in 0 ppm and $350 \mathrm{ppm} \mathrm{CO}_{2}$ than in 2000 ppm $\mathrm{CO}_{2}$ (Figure 1).

\section{Glutathione contents and redox states}

Compensating the low ascorbate content, the glutathione content was highest in $v t c 1$ at the beginning of the fumigation period. Lowest glutathione contents were observed in $a d g 1$, while the glutathione content was similar to $w t$ in pgr1. During the $6 \mathrm{~h}$ fumigation the glutathione content increased in all samples to similar levels and redox states (Figure 1). Although not significantly different, the mean values indicate a trend towards slightly higher reduction at the end of the fumigation period (Figure 1).

Activities of antioxidant enzymes

Compared to $w t$, the three mutants revealed increased ascorbate peroxidase activities in high and low $\mathrm{CO}_{2}$. APx activity of $a d g 1$ was twice that observed in $w t$ at ambient $\mathrm{CO}_{2}$ concentrations (Figure 1). In parallel, the SOD activity was 1.5 -fold induced in adg1. Like for APx the $\mathrm{CO}_{2}$ availability scarcely affected SOD activity of $v t c 1$. SOD and APx activities were only slightly higher in pgr1 than in $w t$, 
while that mutation increased glutathione reductase activity in 0 and $350 \mathrm{ppm} \mathrm{CO}_{2}$ (Figure 1). Surprisingly, SOD and GR activities were lower in 0 than $350 \mathrm{ppm} \mathrm{CO}_{2}$ (Figure 1).

\section{Contents of soluble and hydrolysable sugars}

In $w t$, pgr1 and $v t c 1$ the $\mathrm{CO}_{2}$ availability barely changed the availability of soluble sugars, while in adg1, due to the limitation in chloroplast starch biosynthesis, the sugar

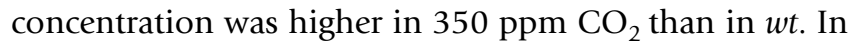
parallel, hydrolysable sugars were generally very low in $a d g 1$ and did not increase in high $\mathrm{CO}_{2}$. pgr1 and vtc1 had similar and slightly higher soluble sugar levels than $w t$ at all $\mathrm{CO}_{2}$ concentrations applied. In contrast, the concentration of hydrolysable sugars was less in $v t c 1$ compared to pgr1, which may reflect the effect of limited GDP-mannose pyrophosphorylase activity on cell wall biosynthesis [27]. Generally, in $w t, v t c 1$ and pgr1 the sugar levels were only elevated at ambient $\mathrm{CO}_{2}$, but not in saturating $\mathrm{CO}_{2}$ demonstrating that in high $\mathrm{CO}_{2}$, in which Calvin-cycle activity should be stimulated, carbon assimilation was limited or carbohydrate consumption activated leading to similar carbohydrate pool sizes as in $0 \mathrm{ppm} \mathrm{CO}_{2}$ (Figure $2 \mathrm{~A}$ and $2 \mathrm{~B}$ ).

\section{ABA levels in ambient air}

Consistent with previous observations [14], the ABA content was increased 2.1-fold in $v t c 1$ compared to $w t$. adg1 and pgr1 showed insignificant increases in the range of 1.2- to 1.3-fold, respectively (Figure 2C).

\section{Photosynthetic performance of wild-type and mutants}

To test $w t$ and mutants for limitations in photosynthetic electron transport, in the final 2 hours of the fumigation period the photosynthetic response of the plants to a 3.6increase in the light intensity from 80 to $285 \mu \mathrm{mol}$ quanta $\mathrm{m}^{-2} \mathrm{~s}^{-1}$ was tested by monitoring chlorophyll-a-fluorescence parameters (Table 2). In ambient air, the quantum yield of photosystem II ( ФPSII, $\left.\left(\mathrm{F}_{\mathrm{M}^{\prime}}-\mathrm{F}_{\mathrm{S}}\right) / \mathrm{F}_{\mathrm{M}^{\prime}}\right)$ was similar at standard light conditions in $w t$, adg1 and $v t c 1$ and slightly higher in pgr1. In response to increased light, it decreased most in pgr1 with a steady-state level of 0.31 . In $v t c 1$, the steady-state ФPSII was highest, while in $w t$ and $a d g 1$ it was slightly lower.

In $0 \mathrm{ppm}$, ФPSII strongly decreased in all plants prior to the increase in light intensity (Table 2 ). In response to the 3 -fold increase in light intensity ФPSII further decreased to levels between 0.032 (adg1) and $0.093(w t)$ indicating severe reduction of photosynthetic electron transport efficiency.

At $2000 \mathrm{ppm} \mathrm{CO}_{2}$ (Table 2), ФPSII of all lines was highest at standard light conditions $\left(\mathrm{F}_{\mathrm{V}} / \mathrm{F}_{\mathrm{M}}\right.$ between 0.663 and 0.734 ) and dropped in response to increased light to lev- els around 0.5 in $w t, a d g 1$ and $v t c 1$ and as low as 0.35 in pgr1.

Transcript level regulation in response to high and low $\mathrm{CO}_{2}$ Semi-quantitative RT-PCR analyses at least in triplicates were performed to assess the transcript regulation of selected genes in leaves $6 \mathrm{~h}$ after fumigation beginning with the respective $\mathrm{CO}_{2}$ concentration (Fig. 3). Compared to $w t$, in $350 \mathrm{ppm} \mathrm{CO}_{2}$ the transcript levels of the plastidic genes $p s a A$ and $p s b A$, which encode core subunits of photoreaction centre I and II, respectively, and that of the nuclear encoded small subunit of RuBisCO were not significantly changed in the mutants adg1, pgr1 and vtc1, reflecting acclimation. The transcript level for ferritin-1 which has been suggested as marker gene for hydrogen peroxide [28] decreased in all mutants. In contrast, transcripts for Bap1, which is a marker gene for singlet oxygen signalling [28], were specifically increased in the ascorbate deficient mutant $v t c 1$.

The transcript levels of the three tested nuclear encoded chloroplast antioxidant enzymes Csd2, sAPx and 2CPA showed mutant specific patterns. Csd2 and sAPx transcript levels were $w t$-like in $v t c 1$, increased in $a d g 1$ and decreased in pgr1, while the 2CPA transcript levels were specifically decreased in adg1. Stp1 transcript amounts, which are suppressed by the cellular carbohydrate availability [29], were doubled in pgr1 and increased 3.5-fold in $v t c 1$, but were unchanged in adg1.

In $a d g 1$ and $p g r 1$, like in $w t$, the transcript levels of the two plastome encoded genes $p s a A$ and $p s a B$ and the nuclear encoded RbcS, Stp1, Bap1 and Ferritin-1 increased in response to 0 and $2000 \mathrm{ppm}$. Fig. 3 gives the transcript modifications in response to depleting or saturating $\mathrm{CO}_{2}$ of wt and mutants each normalized to the respective level in $350 \mathrm{ppm}$. In $v t c 1$, the response of Bap1, which was already strongly increased at $350 \mathrm{ppm}$, was weakest. In $2000 \mathrm{ppm} \mathrm{CO}_{2}$ treated $v t c 1$ psbA transcripts were hardly increased and psaA transcripts were even slightly decreased indicating a specific response pattern of $v t c 1$ to high $\mathrm{CO}_{2}$.

Again the three transcripts for nuclear encoded chloroplast antioxidant enzymes Csd2, sAPx and 2CPA showed specific response patterns. Csd2 hardly responded to changes in the $\mathrm{CO}_{2}$-availability. Only in pgr1, where the transcript levels were decreased at $350 \mathrm{ppm} \mathrm{CO}_{2}$, an increase in 0 and $2000 \mathrm{ppm} \mathrm{CO}_{2}$ was observed. sAPx transcripts, which were decreased in wt Arabidopsis in response to increased and also decreased $\mathrm{CO}_{2}$ availability, strongly decreased in adg1 treated with $2000 \mathrm{ppm} \mathrm{CO}_{2}$ and increased in pgr1 at $0 \mathrm{ppm} \mathrm{CO}_{2}$. In $v t c 1$, the transcript level responded $w t$-like in $0 \mathrm{ppm} \mathrm{CO}_{2}$ and atypically increased in $2000 \mathrm{ppm} \mathrm{CO}_{2}$. $2 \mathrm{CPA}$ transcripts showed the 

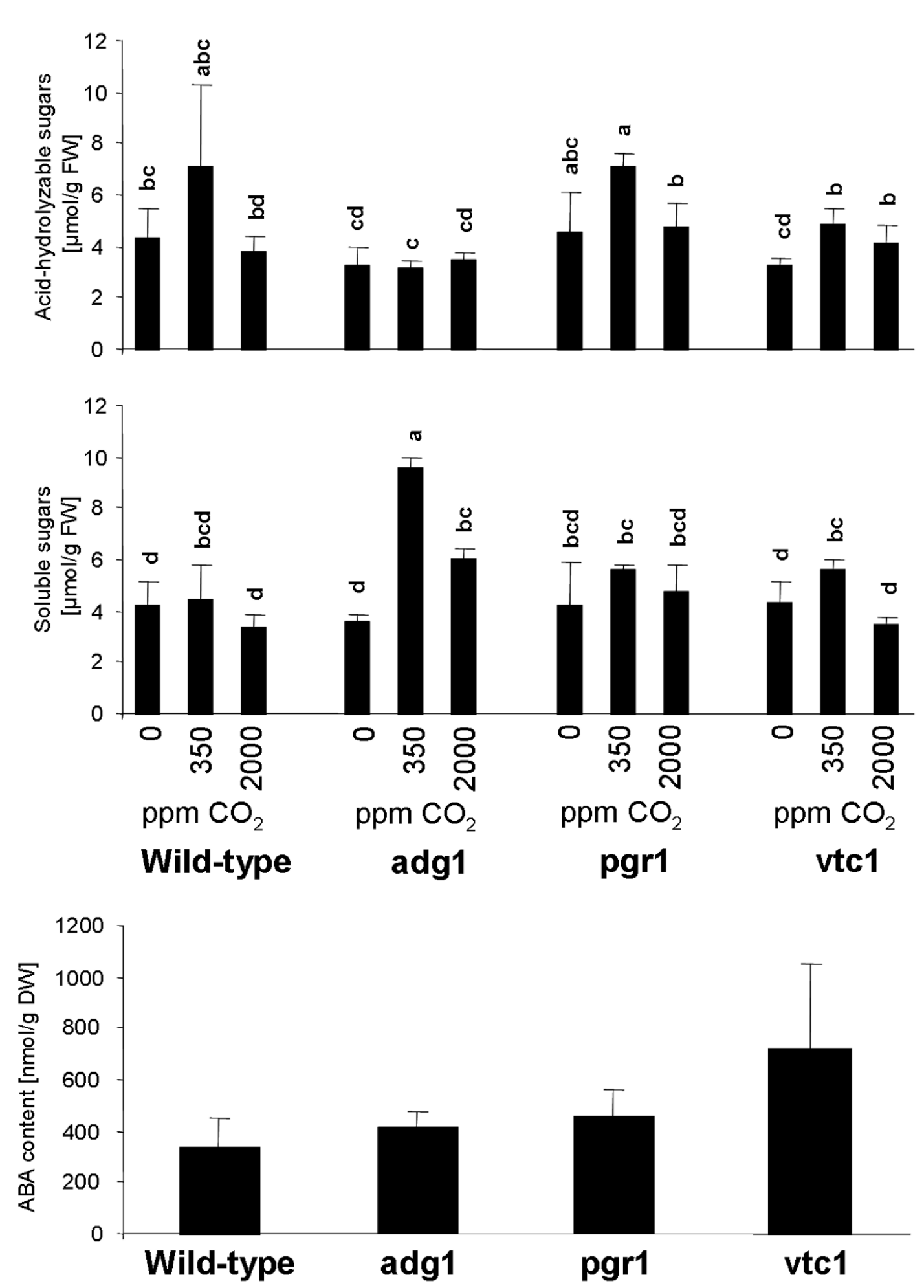

Figure 2

Content of soluble (A) and hydrolyzable sugars (B) in wt, adgl, pgrl and vtcl under different $\mathrm{CO}_{2}$ regimes $(0$ ppm, 350 Ppm and 2000 ppm $C_{2}$ ). The data are means of $n=4-6, \pm$ SE from at least 4 different experiments. Abscisic acid (ABA) content (C) in wt, adgl, pgrl and vtcl after fumigation with $350 \mathrm{ppm} \mathrm{CO}_{2}$. The data are means of $\mathrm{n}=3 \pm \mathrm{SE}$. 
Table 2: Effective quantum yield of PSII at different $\mathrm{CO}_{2}$ regimes $(0 \mathrm{ppm}, 350 \mathrm{ppm}$ and $2000 \mathrm{ppm} \mathrm{CO})$ in response to an increase in the light intensity from 80 to $285 \mu \mathrm{mol}$ quanta $\mathrm{m}^{-2} \mathrm{~s}^{-1}$.

\begin{tabular}{lccccc}
\hline & & wt & adgl & pgrl & vtcl \\
\hline $0 \mathrm{ppm} \mathrm{CO} 2$ & $0 \mathrm{~min}$ & $0.318 \pm 0.071$ & $0.167 \pm 0.050$ & $0.192 \pm 0.090$ & $0.278 \pm 0.063$ \\
& $4.5 \mathrm{~min}$ & $0.093 \pm 0.040$ & $0.032 \pm 0.008$ & $0.071 \pm 0.043$ & $0.051 \pm 0.039$ \\
\hline $350 \mathrm{ppm} \mathrm{CO}_{2}$ & $0 \mathrm{~min}$ & $0.580 \pm 0.039$ & $0.596 \pm 0.029$ & $0.661 \pm 0.033$ & $0.599 \pm 0.041$ \\
& $4.5 \mathrm{~min}$ & $0.388 \pm 0.036$ & $0.395 \pm 0.029$ & $0.314 \pm 0.037$ & $0.437 \pm 0.032$ \\
\hline $2000 \mathrm{Ppm} \mathrm{CO} 2$ & $0 \mathrm{~min}$ & $0.663 \pm 0.025$ & $0.704 \pm 0.022$ & $0.734 \pm 0.012$ & $0.710 \pm 0.019$ \\
& $4.5 \mathrm{~min}$ & $0.518 \pm 0.033$ & $0.482 \pm 0.046$ & $0.345 \pm 0.026$ & $0.519 \pm 0.037$ \\
\hline
\end{tabular}

The data are means of 6 measurements.

previously reported $\mathrm{CO}_{2}$ dependency [30]. The regulation amplitude increased in adg1. The high $\mathrm{CO}_{2}$-response was abolished in pgr1 and reversed to an increased transcript level in $2000 \mathrm{ppm} \mathrm{CO}_{2}$ in $v t c 1$.

\section{Discussion}

Photosynthetic activity and metabolism depend on the stoichiometrical assembly and regulated interaction of nuclear and chloroplast encoded proteins [31]. In addition, changing environmental conditions are continuously sensed and used to adjust the photosynthetic apparatus for balanced supply of energy, reductive power and assimilates. The basic mechanism of regulation involves coordination of gene expression. Although various studies on this topic have identified candidate signals, the complexity of interaction and the multiplicity of signals are far from being understood. Here, a set of biochemical and physiological data and the transcripts were analyzed upon variation of the $\mathrm{CO}_{2}$-availability in order to tentatively identify potential signalling dependencies (Table 3). Approaching $\mathrm{CO}_{2}$ saturation releases the electron pressure within the photosynthetic electron transport chain, increases the acceptor availability at PSI and decreases photorespiration intensity. High quantum yields of PSII (Table 2) indicated efficient electron consumption. Despite metabolic activation, the cellular reduction state of $\mathrm{NADP}(\mathrm{H})$ increased in $w t$ under saturating $\mathrm{CO}_{2}$ (Table 1). In parallel, the ATP availability decreased (Table 1) [6].

\section{Regulation of ROS-responsive genes}

Six hours of illumination in low, ambient or high $\mathrm{CO}_{2}$ elicited significant changes in transcript abundance. The increase of ferritin-1 and Bap1 transcript amounts in 0 and $2000 \mathrm{ppm} \mathrm{CO}_{2}$ indicates redox imbalances and stimulation of ROS signalling in high as well as low $\mathrm{CO}_{2}$ [28]. This is surprising since relaxation of electron pressure should be maximal at saturating $\mathrm{CO}_{2}$ with concomitantly low rates of ROS generation. However, a high activation state of the Calvin cycle needed for efficient carbon fixation at saturating $\mathrm{CO}_{2}$ depends on a highly reduced thioredoxin system that in turn activates the redox regulated enzymes [32]. The increase of ferritin-1 and Bap-1 transcript levels suggests that regulated electron drainage maintains sufficient electron pressure and is involved in the up-regulation of the ROS-related marker genes.

The $\mathrm{CO}_{2}$ dependent response was altered in the mutant genetic backgrounds. In adg1, the Bap1 transcript levels were less induced in $0 \mathrm{ppm}$ and more in $2000 \mathrm{ppm}$ (Figure 3) demonstrating that limitations in chloroplast carbohydrate storage affect the responsiveness of singlet oxygen-signalling. It is tempting to assume that in adg1 increased APx and SOD activities (Figure 1) antagonized Bap1 induction in low $\mathrm{CO}_{2}$ (Figure 3) due to higher antioxidant protection, while the high transcript accumulation in $2000 \mathrm{ppm} \mathrm{CO}_{2}$ results from carbohydrate inhibition of photosynthetic electron transport due to insufficient capacities for starch biosynthesis. Transcript amount co-regulation analysis shows among all genes tested the strongest correlation of Bap1 with the ascorbate content $(\mathrm{K}=-0.74$; Table 3$)$. Consistent with the hypothesis by op den Camp et al. [28] that Bap1 is regulated by singlet oxygen, the antagonistic effect of ascorbate availability and the negative correlation with the activity of antioxidant enzymes supports the conclusion that the overall cellular antioxidant capacity controls Bap1 induction. Because the total glutathione content was significantly decreased in adg1 in $350 \mathrm{ppm}$ at the begin and end of the fumigation time (Figure 1A), a special regulatory function in Bap1-regulation is indicated for the ascorbate-specific components of the Halliwell-Asada-Cycle [33].

In contrast, for ferritin-1, which is supposed to be induced specifically by $\mathrm{H}_{2} \mathrm{O}_{2}[28]$, no such strict correlation was observed with the availability of low molecular weight antioxidants or the activity of antioxidant enzymes. Highest correlation was observed with the availability of hydrolysable sugars $(\mathrm{K}=-0.62$; Table 3$)$ suggesting regulation by carbohydrate metabolism. A similar negative correlation with the contents of hydrolysable sugars was observed for Stp1, which encodes a plasma-membrane 


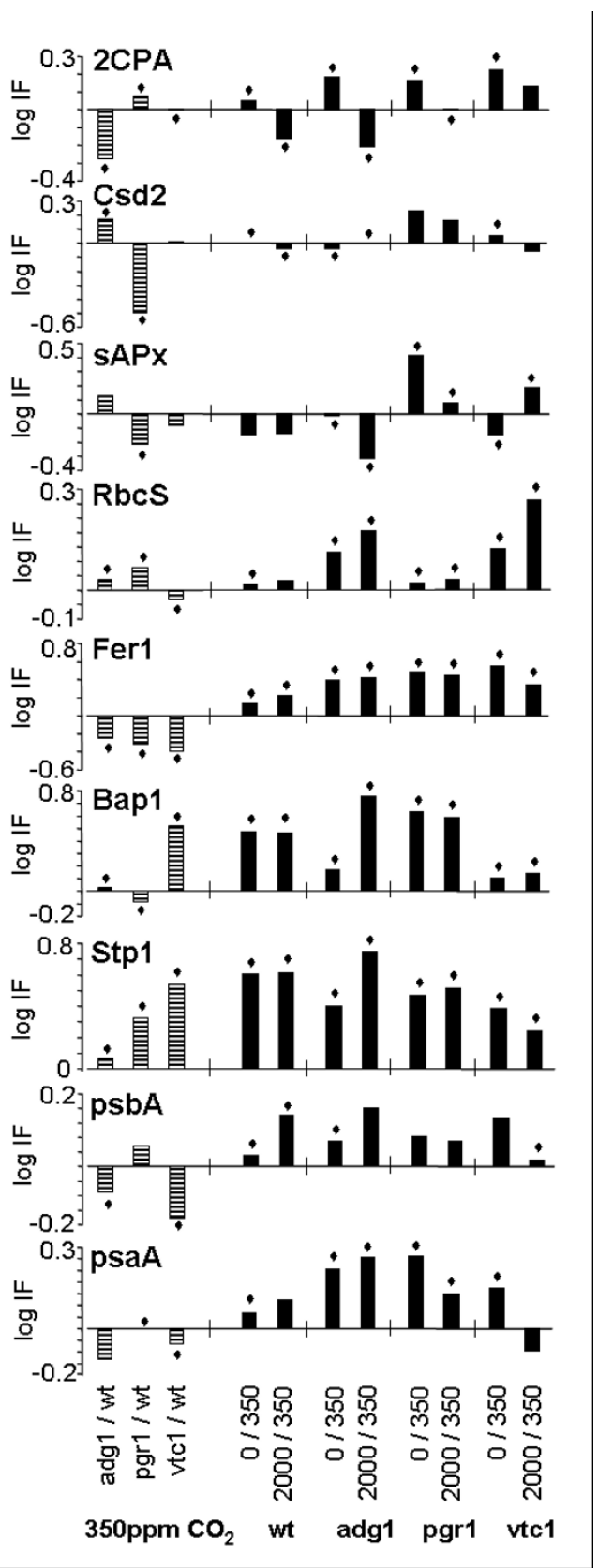

Figure 3

Semi-quantitative RT-PCR data of selected plastome and nuclear encoded genes. The PCR products were separated on ethidium bromide containing agarose gels and documented electronically in UV light and analyzed densitometrically. The values are given as the logarithm of the induction factor which is calculated from the ratio of transcript level of WT and mutants at ambient $350 \mathrm{CO}_{2}$ (hatched bars). The black bars represent logarithmic values calculated after fumigation with 0 or $2000 \mathrm{ppm} \mathrm{CO}$, respectively, in relation to corresponding control at $350 \mathrm{ppm} \mathrm{CO}_{2}$ for wt, adg l, pgrl and vtcl. The data are means of $n=3,(\diamond)$ indicates that the SD was less than $30 \%$ of the mean value. monosaccharide transporter [29]. Even stronger than for ferritin-1 transcript abundance and Bap1 transcript abundance, for Stp1 a positive correlation with the glutathione content and the redox state of the glutathione pool was observed (Table 3) suggesting glutathione-dependent regulation. However, excluding adg1-data from the correlation analysis demonstrated that at least for Bap1 and Stp1 the high correlation with glutathione data results from the adg1-specific regulation of the glutathione pool and, therefore, may also result from disturbed chloroplast carbohydrate metabolism.

\section{Ascorbate-dependent regulation}

In a genome-wide transcript analysis of $v t c 1$ plants, Pastori et al. [14] identified 171 genes with altered expression, among which defence genes constituted a significant subgroup. Here, in the steady state, in $350 \mathrm{ppm} \mathrm{CO}_{2}$, to which the plants were adapted to, the transcript levels of 2CPA, Csd2 and sAPx were balanced. The transcript level of ferritin-1 was even decreased. The transcript level of Bap-1 was 3.73-fold increased and constitutively high upon variation of the $\mathrm{CO}_{2}$-availability, demonstrating that the transcript abundance is dominantly regulated by the mutational defect in ascorbate biosynthesis.

The transcript levels of Bap1, Fer1, RbcS and Stp1, although to different extends, negatively correlated with the ascorbate content and positively with the reduction state. Apparently metabolically induced alterations in ascorbate levels caused similar transcriptional changes as genetic mutations in ascorbate biosynthesis [14]. In our analysis the correlation between ascorbate and defence gene expression was stronger when the data set of the vtc1mutant was not included $(\mathrm{K}=-0.67)$ demonstrating that in $v t c 1$ hardening responses may mask signalling induced by the variation of $\mathrm{CO}_{2}$-availability.

The strongest relationship between the reduction state of ascorbate and transcript level regulation was observed for 2CPA. In previous experiments strong suppression of 2CPA transcription was observed upon ascorbate application $[29,34,35]$. Here, responses upon internal variation of the ascorbate content were analyzed. A strong negative correlation (-86\%; Table 3) with the reduction state of ascorbate, but absence of correlation with the ascorbate content $(\mathrm{K}=0.23$; Table 3$)$ excludes sensing the ascorbate availability. It is postulated that either specifically dehydroascorbate or, more likely, the electron consumption in dehydroascorbate reduction regulates 2CPA transcript abundance.

\section{Coupling of transcript abundance regulation}

A set of four genes, i.e. Bap1, psaA, psbA and Stp1, showed a similar transcript pattern in response to the seven metabolic parameters, i.e. glutathione contents and reduction 
Table 3: Correlation analysis of metabolite data, enzyme activities and transcript levels.

\begin{tabular}{|c|c|c|c|c|c|c|c|c|c|}
\hline & $\mathrm{psaA}$ & psbA & $2 \mathrm{CPA}$ & sAPx & Csd2 & RbcS & Bapl & Fer & Stp I \\
\hline PSII [0 min] & -0.28 & -0.08 & $-0.34^{*}$ & -0.22 & -0.17 & +0.07 & -0.12 & +0.08 & -0.11 \\
\hline PS II [4.5 min] & $-0.38 *$ & -0.14 & $-0.33 *$ & +0.03 & -0.03 & +0.07 & -0.09 & +0.24 & -0.15 \\
\hline ATP & -0.12 & $-0.39 *$ & $+0.58 *$ & +0.03 & $+0.35 *$ & -0.03 & -0.19 & -0.12 & -0.24 \\
\hline ADP & -0.10 & -0.22 & +0.09 & +0.23 & +0.28 & +0.18 & -0.20 & +0.09 & -0.21 \\
\hline ATP/ADP & +0.05 & -0.07 & $+0.41 *$ & $-0.31 *$ & +0.19 & -0.01 & +0.14 & -0.19 & +0.09 \\
\hline Soluble Sugars & -0.01 & +0.01 & +0.02 & $-0.35 *$ & -0.7 I** & $-0.33 *$ & -0.25 & $-0.34 *$ & -0.20 \\
\hline Hydrolyzable Sugars & $-0.43 *$ & $-0.46 *$ & +0.12 & +0.07 & $+0.47 *$ & -0.29 & $-0.45 *$ & $-0.62 * *$ & $-0.60 * *$ \\
\hline 3PGA & $-0.51 *$ & $-0.41 *$ & -0.07 & +0.02 & -0.07 & $-0.36 *$ & $-0.55^{*}$ & $-0.32 *$ & $-0.63 * *$ \\
\hline DHAP & $+0.50 *$ & $+0.39 *$ & $+0.35^{*}$ & -0.27 & $+0.36 *$ & +0.10 & $+0.34 *$ & +0.25 & $+0.48 *$ \\
\hline$[\mathrm{NADPH} / \mathrm{NADP}+]_{\mathrm{calc}}$ & $+0.52^{*}$ & $+0.40 *$ & +0.09 & +0.08 & +0.15 & +0.23 & $+0.33 *$ & $+0.32 *$ & $+0.47 *$ \\
\hline Assimilatory Force & $+0.49 *$ & +0.29 & $+0.42 *$ & -0.08 & +0.24 & +0.17 & $+0.30 *$ & +0.16 & $+0.43 *$ \\
\hline Ascorbate Content & -0.08 & -0.04 & +0.23 & +0.29 & +0.02 & $-0.4 I *$ & $-0.74 * *$ & $-0.32 *$ & $-0.46 *$ \\
\hline Ascorbate \%red & -0.10 & +0.16 & $-0.86 * *$ & -0.25 & +0.01 & $+0.47^{*}$ & $+0.50 *$ & $+0.30 *$ & $+0.43 *$ \\
\hline GSH Content & $+0.61^{* *}$ & $+0.64 * *$ & -0.14 & +0.02 & $-0.67 * *$ & -0.13 & $+0.54^{*}$ & $+0.46 *$ & $+0.67 * *$ \\
\hline GSH \% red & $+0.41^{*}$ & $+0.37 *$ & -0.02 & -0.08 & $-0.46 *$ & +0.09 & $+0.46 *$ & $+0.35^{*}$ & $+0.60 * *$ \\
\hline CAT Activity & -0.13 & -0.11 & +0.22 & $+0.37 *$ & -0.11 & $-0.46 *$ & $-0.44 *$ & +0.10 & -0.24 \\
\hline SOD Activity & $-0.56 *$ & $-0.41 *$ & -0.21 & -0.12 & $+0.80 * *$ & $+0.46 *$ & -0.27 & $-0.38 *$ & $-0.5 I *$ \\
\hline GR Activity & $-0.33 *$ & -0.23 & -0.11 & +0.20 & $-0.38 *$ & $-0.56 *$ & -0.24 & -0.27 & $-0.34 *$ \\
\hline total APx Activity & $-0.59 *$ & $-0.44 *$ & $-0.39 *$ & -0.10 & $+0.70 * *$ & $+0.60 * *$ & -0.24 & $-0.31 *$ & $-0.45 *$ \\
\hline
\end{tabular}

The table shows the correlation coefficient $\mathrm{K}$ calculated between metabolite, enzyme activities and every single transcript detected by semiquantitative RT-PCR. Bold printed numbers with '*' stand for $0.3<|\mathrm{K}|<0.6$ and bold printed numbers with ' $* *$ ' for strong negative and positive correlations $0.6=|\mathrm{K}|$.

state, 3-PGA and DHAP contents, the calculated NADPH reduction state and assimilatory force, and the hydrolysable sugars (Table 3). It should be noted that transcript levels of psaA and psbA changed in parallel in response to the imposed metabolic and mutational strains. This contrasts the anti-parallel responses of psaAB and psbB observed upon transfer to photosystem I and II-specific light regime previously described by Pfannschmidt et al. [11]. It is concluded that a variation between 0 and $2000 \mathrm{ppm} \mathrm{CO}_{2}$ in the mutant background elicits more severe changes in metabolism and signalling than altering the light quality from red to far red at very low photon flux density [11]. However, the photosystem I transcript psaA decreased relative to the photosystem II transcript psbA when the electron pressure was reduced by increasing the $\mathrm{CO}_{2}$ availability (Figure 3), e.g. from $1.07(0 \mathrm{ppm})$ to $1(350$ $\mathrm{ppm})$ to $0.88(2000 \mathrm{ppm})$ in $w t$ indicating a stronger transcription of genes for the PS-I reaction centre protein in 0 ppm $\mathrm{CO}_{2}$ and those encoding PS-II reaction centre proteins in $2000 \mathrm{ppm} \mathrm{CO}_{2}$. In adg1, the gradual response was unaffected, however generally the transcript abundance of psbA was higher than that of psaA (Figure 3). In pgr1 the relative transcript abundance normalized to $w t$ at 350 ppm was also higher under all three $\mathrm{CO}_{2}$ conditions, suggesting that the higher psbA transcript levels were caused by photoinhibitory high carbohydrate availability or a limitation in the Rieske activity.
It is tempting to suggest that the signal is transmitted by PQ-dependent redox signals. However, in $v t c 1$ more $p s a A$ than $p s b A$ was observed at $350 \mathrm{ppm} \mathrm{CO}_{2}$, a balanced $\mathrm{psaA} / \mathrm{psbA}$ ratio in $0 \mathrm{ppm} \mathrm{CO}_{2}$ and an inverted ratio in $2000 \mathrm{ppm}$, demonstrating that the ascorbate availability affects the stoichiometry of transcripts for the photoreaction centres upon variation of the $\mathrm{CO}_{2}$-availability. After $6 \mathrm{~h}$ fumigation with $350 \mathrm{ppm} \mathrm{CO}_{2}$, the steady state quantum yield of PS-II $\left(\left(\mathrm{F}_{\mathrm{M}^{\prime}}-\mathrm{F}_{\mathrm{S}}\right) / \mathrm{F}_{\mathrm{M}^{\prime}}\right)$ was wt-like (Table 2$)$, while the quantum yield was adjusted to 1.23 -fold higher levels within 4.5 min of illumination upon doubling of the light intensity (Table 2). On the background of decreased ascorbate availability (Figure 2A) this demonstrates that the photosynthetic electron transport chain was otherwise protected. Chlorophyll fluorescence analysis showed that the acclimation was insufficient to protect the photosynthetic membrane in low $\mathrm{CO}_{2}$. The low quantum yield of PS-II (Table 2) demonstrates even stronger photosynthetic impairment than in $w t$. That the regulation of the quantum yield of PS-II does not correlate with the psaA/psbA-ratios, supports the hypothesis that the regulation of the transcript abundance of the photoreaction centre proteins is more dependent on ascorbate-specific signals than on the redox state of the PQ-pool. The PQ-dependent long term acclimation response postulated by Pfannschmidt et al. [11] appears further subordinate to signals linked to the metabolic state of the PGA and 
DHAP concentrations, the NADPH/NADP+ ratio, the assimilatory force and hydrolysable sugars (Table 3). In adg1 a perfect positive correlation $(K=1)$ was observed between the concentration of soluble sugars and the psbA transcript levels, whereas the other lines showed a high negative correlation ( $w t: \mathrm{K}=-1 ;$ pgr1 : $\mathrm{K}=-0.96 ; v t c 1: \mathrm{K}=-$ 1), highlighting the importance of carbohydrate-dependent signals in psaA and psbA regulation.

\section{Correlation with the adenylate status}

In animals, the energy status sensed for instance via insulin-like growth factor 1 or by AMP-dependent kinases plays an important role in regulation of gene expression [36]. However, here except an only weak $(K=0.41)$ correlation for 2CPA, no correlations between the adenylate status and transcript levels were indicated. Due to the photoautotrophic nature of plants, plants rarely encountered energy deprivation. Further on, the chloroplast and cellular adenylate status directly coordinates metabolic pathways via feed-back and feed-forward mechanisms [37]. The lack of strong energy-linked regulation demonstrates that the adenylate phosphorylation state may not be a major signal, which is directly linked to the regulation of nuclear gene expression in context of photosynthesis.

However, the analysis of pgr1 showed a mutant specific regulation of Csd2, sAPx and 2CPA upon altered $\mathrm{CO}_{2}-$ availability (Figure 3 ). Because $p g r 1$ is unable to acidify the thylakoid lumen below $\mathrm{pH} 6$ due to a mutation in the Rieske protein [18], the ATP/ADP ratio was very low in the morning and generally decreased irrespective of the $\mathrm{CO}_{2}$ concentration (Table 1). The concentrations of most metabolites were not significantly changed in response to altered $\mathrm{CO}_{2}$ availability compared to $w t$ indicating efficient metabolic compensation (Figure 3). The transcript levels of Csd2, sAPx and 2CPA were regulated in a mutant specific manner, while RbcS, Bap1, Fer1 and Stp1 responded $w t$-like demonstrating that ROS- and carbohydrate signalling pathways were unaffected $[28,29,38]$. Upon the different treatments of pgr1 the transcript abundance of sAPx highly correlated with the calculated reduction state of NADPH (K=0.99), while no correlation was observed in the other plant lines. It is therefore concluded that the mutation in the Rieske protein limits the finecontrol of sAPx expression and makes it more dependent on stromal redox signals. The difference in sAPx regulation between pgr1 and $w t$ also demonstrates that in $w t$ the Rieske protein influences sAPx expression. Excluding ROS-signalling, because the Bap1 control was wt-like, either the redox state of the PQ pool or thylakoid acidification/the adenylate status may modulate sAPx transcript abundance.
The Csd2 transcript levels positively correlated with APx activity in all lines under all treatments (Table 3). Concomitantly, in pgr1, also an almost perfect correlation was observed with the redox state of NADPH. Compared to sAPx the Csd2 transcript level was regulated with higher amplitudes. sAPx and Csd2 transcripts encode two prominent chloroplast antioxidant enzymes, which successively act in superoxide and $\mathrm{H}_{2} \mathrm{O}_{2}$ detoxification in the stromal part of the Halliwell-Asada cycle (ascorbatedependent water-water cycle) [33]. Coordinated regulation of transcript abundance points out expressional coregulation.

\section{Conclusion}

In the cell, metabolite, redox and energy signals are tightly linked, which makes differentiation of signalling cascades difficult. This study demonstrates that comparison of mutants with specific limitations in the coordination of plant acclimation at least transiently uncouples signalling branches. Comparison of adg1, pgr1 and vtc1 with Arabidopsis wild-type plants showed coordinated expression of Bap1, psaA, psaA and Stp1, which have been discussed previously to respond specifically to singlet oxygen [28], the redox state of the PQ pool [11] and monosaccharide availability [29], respectively. Like Ferritin-1, Bap1 and Stp1 correlated strongest with the ascorbate contents, while for psaA and psbA a stronger link to the assimilatory force and NADPH/NADP ${ }^{+}$ratio was indicated. Correlation of 2CPA expression, whose transcription is controlled by the acceptor availability at photosystem I in $w t$ [30], with the redox state of the ascorbate pool further strengthens the links between the antioxidant system and the photosynthetic electron transport and more specifically chloroplast-to-nucleus signalling. It is postulated that during evolution a stabilized network has evolved which links photosynthetic metabolism to nuclear gene expression. Mutants might be well balanced under standard conditions, but application of environmental changes leads to an altered acclimation in comparison to $w t$, which allows to tentatively differentiate parallel induced signalling cascades.

\section{Methods \\ Plant material and growth conditions}

Arabidopsis thaliana wt (Col-0), the mutants adg1 [16], pgr1 [15] and $v t c 1$ [17] grew in controlled environment $(10 \mathrm{~h}$ of light, $100 \mu \mathrm{mol}$ quanta $\mathrm{m}^{-2} \mathrm{~s}^{-1}, 23^{\circ} \mathrm{C}$ and $14 \mathrm{~h}$ darkness at $18^{\circ} \mathrm{C} ; 50 \%$ relative humidity) on a $1: 1: 1$ mixture of Frühsdorfer Erde Klocke $\mathrm{P}$, perlite and vermiculite for 5 weeks. Beginning $2 \mathrm{~h}$ after onset of light, sets of plants ( $w t$, adg1, pgr1 and vtc1) were fumigated for $6 \mathrm{~h}$ with synthetic air in 281 Perspex chambers or 5-1 Sekuroka ${ }^{\circledR}$ glove bags with 0 and 2000 ppm $\mathrm{CO}_{2}$, respectively, or maintained in ambient air. A Millipore Tylan RO 7030 system controlled the gas flow at $2 \mathrm{l} / \mathrm{min}$. 


\section{Metabolite analysis}

Total and reduced ascorbate was quantified spectrophotometrically according to [39] from plant material frozen in liquid nitrogen by recording the decrease of absorption at $265 \mathrm{~nm}$ following addition of ascorbate oxidase. Glutathione contents were determined fluorimetrically after derivatization with monobromobimane and HPLC separation on a "reverse phase" Hypersil BDS-C15 $5 \mu \mathrm{m}$ column from tissue extracted in $0.1 \mathrm{M} \mathrm{HCl}$ and $5 \mathrm{mM}$ diethylenetriamine pentaacetic acid [40]. 3-PGA and DHAP contents of perchloric acid extracts were quantified according to Dietz \& Heber [41], ATP and ADP with firefly enzyme according to the luminometric method described by Kaiser \& Urbach [42]. Assimilatory force and NADPHreduction state were calculated as described in Dietz \& Heber [24]. Reducible hydrolysable and soluble sugars were determined according to Yemm \& Willis [43] with anthrone reagent. ABA contents were quantified according to Weiler [44] from freeze-dried leaf material.

\section{Chlorophyll-a-fluorescence measurements}

Between 4-6 $\mathrm{h}$ after onset of the $\mathrm{CO}_{2}$ fumigation, the response of the mutants to an increase in light intensity to $285 \mu \mathrm{mol}$ quanta $\mathrm{m}^{-2} \mathrm{~s}^{-1}$ was monitored for 4 min using a Mini-PAM Fluorometer (Walz, Effeltrich, Germany). $30 \mathrm{~s}$ before and during the illumination with $285 \mu$ mol quanta $\mathrm{m}^{-2} \mathrm{~s}^{-1}$, the fluorescence parameters $\mathrm{F}_{\mathrm{S}}$ and $\mathrm{F}_{\mathrm{M}^{\prime}}$ [45] were determined every $30 \mathrm{~s}$ with saturating light pulses (1s; $>3000 \mu \mathrm{mol}$ quanta $\left.\mathrm{m}^{-2} \mathrm{~s}^{-1}\right)$. The quantum yield of PS-II (ФPSII) was calculated as $\left(\mathrm{F}_{\mathrm{M}^{\prime}}-\mathrm{F}_{\mathrm{S}}\right) / \mathrm{F}_{\mathrm{M}^{\prime}}$.

\section{Determination of protein contents and biochemical analyses of enzyme activities}

Enzyme activities were determined according to [34] and standardized on protein contents of the samples determined with the BIORAD protein assay (BioRad Laboratories, München, Germany).

\section{RNA isolation, CDNA synthesis and RT-PCR analysis}

Approximately $100 \mathrm{mg}$ plant material pulverized in liquid nitrogen was extracted in $500 \mu \mathrm{l} 100 \mathrm{mM}$ Tris-HCl, $\mathrm{pH}$ 8.5, 25 mM EDTA, 25 mM EGTA, 100 mM $\beta$-mercaptoethanol and $2 \%$ SDS with $500 \mu \mathrm{l}$ phenol and $300 \mu \mathrm{l}$ chloroform. The aqueous phase was re-extracted first with $1 \mathrm{ml}$ phenol/chloroform (1:1), then with $1 \mathrm{ml}$ chloroform prior to precipitation of the RNA at $4^{\circ} \mathrm{C}$ by addition of 1 $\mathrm{ml}$ isopropanol. For further purification the precipitate was dissolved in $10 \mathrm{mM}$ Tris, $1 \mathrm{mM}$ EDTA, re-precipitated with 3 volumes $8 \mathrm{M} \mathrm{LiCl}$ and washed with $70 \%$ ethanol. The RNA dissolved in DEPC-treated water was quantified spectrophotometrically. Residual DNA was removed by treatment with RNase-free DNase (1 U; Promega). Prior to cDNA synthesis, the DNase was inactivated by adding EDTA to a final concentration of $2.5 \mathrm{mM}$ and by incubation at $70^{\circ} \mathrm{C}$ for $20 \mathrm{~min} .5 \mu \mathrm{g}$ DNase treated RNA was used for cDNA synthesis using oligo(dT) and a primer mix containing a mixture of oligonucleotides matching all plastidencoded genes as primers [46] for $1 \mathrm{~h}$ at $42^{\circ} \mathrm{C}$. The samples were standardized on actin- 2 transcript amount. Genes of interest were analysed by semi-quantitative RTPCR (PCR settings: 1 cycle at $94^{\circ} \mathrm{C}$ for $3 \mathrm{~min}$, for the optimized number of cycles: $45 \mathrm{~s} 94^{\circ} \mathrm{C}, 30 \mathrm{~s} 50^{\circ} \mathrm{C}$, and $15 \mathrm{~s}$ $72^{\circ} \mathrm{C}$ ). Following separation of the PCR products on ethidiumbromide stained agarose gels, the bands were quantified densitometrically [34]. Each band was normalized against the intensity obtained with the same cDNA using the actin-specific primers. The primers and gene code numbers were as follows: actin (At5g09810) sense 5'TACAACGAGCTTCGTGTTGC-3', antisense 5'GGACAACGGAATCTCTCAGC-3'; psbA (AtCg00020) sense 5'-GAAAATCAATCGGCCAAAAT-3', antisense 5'TTACCCAATCTGGGAAGCTG-3'; psaA (AtCg00350) sense 5'-GATCTAATCCGCCACGAAAA-3', antisense 5'CAGGTGGTTTGGCCAATAGT-3'; RbcS (all isoforms) sense 5'-AGAAGTAATGGCTTCCTC-3', antisense 5'AAGCTTCGGTGAAGCTTG-3'; Csd2 (At2g28190) sense 5'-CTCCGTTCCTCTTTCAGC-3', antisense 5'-GCGTCAAGCCAATCACAC-3'; 2CPA (At3g11630) sense 5'CTCTCCATCTGTTTCTTT-3', antisense 5'-GTACCTTTTTCGTATCAT-3'; sAPx (At4g08390) sense 5'-TGTTCCAGTTAGCTAGTG-3', antisense 5'GGTTGAGTAAATTAGGTGC-3'; Fer1 (At5g01600) sense 5'-ATGGCCTCAAACGCACTCT-3', antisense 5'-CTAGTCCCTTCATAGCAACG-3', Bap1 (At3g61190) sense 5'CTAAACCGGAGACCCATC-3', antisense 5'-AGTGACCTTCAGGTGAATAC-3'; Stp1(AT1g11260) sense 5'-TTCTTTCAACAGCTAACCGGA-3', antisense 5'GGCTAATACACTTTTTCCTTTA-3'.

\section{Statistical analysis}

From the calculated means and standard deviations the significance of differences was determined by Student's $t$ test. Data sets were designated significantly different, if the $P$ value was below 0.05 . Coefficiency analysis was performed by Pearson correlation analysis. Coefficients higher than $r=|0.6|$ was defined as strong correlation, and between $|0.3|$ and $|0.6|$ as weak correlations.

\section{Abbreviations}

2CP: 2-cysteine peroxiredoxin; 3-PGA: 3-phosphoglycerate; APx: ascorbate peroxidase; cDNA: copy DNA; Csd: cupper/zinc superoxide dismutase; DEPC: diethyl pyrocarbonate; DHAP: dihydroxyacetone phosphate; $\mathrm{F}_{\mathrm{A}}$ : assimilatory force; FW: fresh weight; $\mathrm{PQ}$ : plastoquinone; Prx: peroxiredoxin; PS: photosystem; ROS: reactive oxygen species; RT-PCR: amplification of transcripts by polymerase chain reaction after reverse transcription into cDNA; RuBisCO: ribulose-1,5-bisphosphate carboxylase/ oxygenase; SOD: superoxide dismutase; $w t$ : wild-type 


\section{Authors' contributions}

DW carried out the metabolite analyses, most of the gene expression analyses, performed the statistical analysis and contributed to writing the manuscript. MB performed preparatory work for the gene expression analysis, carried out the chlorophyll-a fluorescence analysis, was involved in designing and validation of the project and contributed to writing of the manuscript. AK was involved in transcript analysis and project development, and helped with the manuscript, RS provided technical support and discussion, WH determined the ABA-contents and K-JD was the principal investigator who coordinated the project and was involved in data interpretation and writing of the manuscript. All authors agreed on the final manuscript.

\section{Acknowledgements}

The work was performed within the framework of FOR 387 (TPI, TP3 and TPI0) funded by the DFG.

\section{References}

I. Rolland F, Moore B, Sheen J: Sugar sensing and signaling in plants. The Plant Cell 2002, I 4:185-205.

2. Demidchik V, Nichols C, Oliynyk M, Dark A, Glover BJ, Davies JM: Is ATP a signaling agent in plants? Plant Physiology 2003, | 33:456-46|.

3. Baier M, Dietz K-J: Chloroplasts as source and target ofcellular redox regulation: a discussion on chloroplast redox signals in context of plant physiology. Journal of Experimental Botany 2005, 56: | 449-| 462.

4. Koch KE: Molecular crosstalk and the regulation of $\mathbf{C}$ - and $\mathbf{N}$ responsive genes. In $\boldsymbol{A}$ molecular approach to primary metabolism in higher plants. In Taylor and Francis, London Foyer CH, Quick WP; 1997: 105-I24.

5. Edmondson DL, Badger MR, Andrews TJ: Slow inactivation of ribulose bisphosphate carboxylase during catalysis is caused by accumulation of a slow, tight-binding inhibitor at the catalytic site. Plant Physiology 1990, 93:1390-1397.

6. Dietz K-J, Heber U: Rate-limiting factors in leaf photosynthesis: I. Carbon fluxes in the Calvin Cycle. Biochimica Biophysica Acta 1984, 767:432-443.

7. Ruuska SA, Badger MR, Andrews TJ, von Caemmerer S: Photosynthetic electron sinks in transgenic tobacco with reduced amounts of Rubisco: little evidence for significant Mehler reaction. Journal of Experimental Botany 2000, $51: 357-368$.

8. Allen JF: Control of gene expression by redox potential and the requirement of chloroplast and mitochondrial genomes. Journal of Theoretical Biology 1993, 165:609-63I.

9. Dietz K-J, Schreiber U, Heber U: The relationship between the redox state of $Q_{A}$ and photosynthesis in leaves at various carbon-dioxide, oxygen and light regimes. Planta 1985, 166:219-226.

10. Frilyand LE, Scheibe R: Controlled distribution of electrons between acceptors in chloroplasts. A theoretical consideration. Biochimica Biophysica Acta 1999, | 4 | 3:3 |-42.

II. Pfannschmidt T, Allen JE, Oelmüller R: Principles of redox control in photosynthetic gene expression. Physiologia Plantarum 200I, I I 2: I-9.

12. Dietz K-J: Redox regulation, redox signalling and redox homeostasis in plant cells. International Review of Cytology 2003, 228: $14 \mid-193$.

13. Eskling M, Avidsson P-O, Åkerlund HE: The xanthophyll cycle, its regulation and components. Plant Physiology 1997, 100:806-816.

14. Pastori GM, Kiddle G, Antoniw J, Bernard S, Veljovic-Jovanovic S, Verrier PJ, Noctor G, Foyer CH: Leaf vitamin C contents modulate plant defense transcripts and regulate genes that control development through hormone signaling. The Plant Cell 2003, I5:939-951.

15. Munekage Y, Takeda S, Endo T, Jahns P, Hashimoto T, Shikanai T: Cytochrom $b_{6} f$ mutation specifically affects thermal dissipa- tion of absorbed light energy in Arabidopsis. The Plant Journal 200I, 28:35I-359.

16. Wang S, Lue WL, Yu TS, Long JH, Wang CN, Eimert K, Chen J: Characterization of ADGI, an Arabidopsis locus encoding for ADPG pyrophosphorylase small subunit, demonstrates that the presence of the small subunit is required for large subunit stability. The Plant Journal 1998, 13:63-70.

17. Conklin PL, Norris SR, Wheeler GL, Williams EH, Smirnoff N, Last RL: Genetic evidence for the role of GDP-mannose in plant ascorbic acid (vitamin C) biosynthesis. Proceedings of the National Academy of Science of the USA 1999, 96:4198-4203.

18. Jahns P, Graf M, Munekage Y, Shikanai T: Single point mutation in the Rieske iron-sulfur subunit of cytochrome $b_{6} / f$ leads to an altered $\mathrm{pH}$ dependence of plastoquinone oxidation in Arabidopsis. FEBS Letters 2002, 519:99-102.

19. Haraux F, de Kouchkovsky Y: Energy coupling and ATP synthase. Photosynthesis Research 1998, 57:23I-25I.

20. Li XP, Gilmore AM, Caffarri S, Bassie R, Golan T, Kramer D, Niyogi KK: Regulation of photosynthetic light harvesting involves intrathylakoid lumen $\mathbf{p H}$ sensing by the psbS protein. Journal of Biological Chemistry 2004, 279:22866-22874.

21. Pfündel EE, Dilley RA: The pH dependence of violaxanthin deepoxidation in isolated pea chloroplasts. Plant Physiology 1993 , |01:65-7|.

22. Heber U, Gerst U, Krieger A, Neimanis S, Kobayashi Y: Coupled cyclic electron transport in intact chloroplasts and leaves of C3 plants: Does it exist? If so, what is its function? Photosynthesis Research 1995, 46:269-275.

23. Goldschmidt E, Huber S: Regulation of photosynthesis by endproduct accumulation in leaves of plants storing starch, sucrose and hexose sugars. Plant Physiology 1992, 99: I 443- 1448.

24. Dietz K-J, Heber U: Assimilatory force and regulation of photosynthetic carbon reduction in leaves. In Techniques and new developments in photosynthesis Edited by: Barber J. NATO ASI Series, Plenum Press, New York; 1989:34I-363.

25. Siebke K, Dietz K-J, Heber U: Assimilatory force in illuminated leaves grown in sun or shade or under mineral deficiency. In Current Research in Photosynthesis Volume IV. Edited by: Baltscheffsky M. Kluwer Academic Publishers, Dordrecht; 1990: 19753- 19756.

26. Foyer $\mathrm{CH}$, Lelandais $\mathrm{M}$, Kunert $\mathrm{KJ}$ : Photooxidative stress in plants. Physiologia Plantarum 1994, 92:696-717.

27. Smirnoff N, Wheeler GL: Ascorbic acid in plants: Biosynthesis and function. Critical Reviews in Biochemistry and Molecular Biology 2000, 35:29I-3I4.

28. op den Camp RGL, Prybyla D, Ochsenbein C, Laloi C, Kim AD, Wagner D, Hideg E, Göbel C, Feussner I, Nater M, Apel K: Rapid induction of distinct stress responses after the release of singlet oxygen in Arabidopsis. The Plant Cell 2003, 15:2320-2332.

29. Sherson SM, Hemmann G, Wallace G, Forbes S, Germain V, Stadler R, Bechtold N, Sauer N, Smith SM: Monosaccharide/proton symporter AtStp I plays a major role in uptake and response of Arabidopsis seeds and seedlings to sugar. The Plant Journal 2000, 24:849-857.

30. Baier M, Ströher E, Dietz K-J: The acceptor availability at photosystem $I$ and ABA control nuclear expression of 2-Cys peroxiredoxin-A in Arabidopsis thaliana. Plant and Cell Physiology 2004, 45:997-1006.

31. Leister D, Schneider A: From genes to photosynthesis in Arabidopsis thaliana. International Review of Cytology 2003, 228:3 I-83.

32. Schürmann $P$, Jacquot J-P: Plant thioredoxin system revisited. Annual Reviews of Plant Physiology and Plant Molecular Biology 2000, $51: 37 \mid-400$.

33. Asada K: The water-water cycle as alternative photon and electron sink. Philosophical Transactions of the Royal Society 2000, 355:|4|9-|43|.

34. Baier M, Noctor G, Foyer CH, Dietz K.-J: Antisense suppression of 2-cysteine peroxiredoxin in Arabidopsis specifically enhances the activities and expression of enzymes associated with ascorbate metabolism but not glutathione metabolism. Plant Physiology 2000, I 24:823-832.

35. Horling F, Baier M, Dietz K-J: The cellular redox poise regulates expression of the peroxide detoxifying chloroplast 2-Cys peroxiredoxin in the liverwort Riccia fluitans. Planta 200I, 2 | 4:304-3।3. 
36. Stuart JA, Brown MF: Energy, quiescence and the cellular basis of animal life spans. Comparative Biochemistry and Physiology A: Molecular Integrative Physiology 2006, 143:12-23.

37. Noctor G, Foyer $\mathrm{CH}$ : Homeostasis of adenylate status during photosynthesis in a fluctuating environment. Journal of Experimental Botany 2000, 5 I:347-356.

38. Krapp A, Hofmann B, Schäfer C, Stitt M: Regulation of the expression of rbcS and other photosynthetic genes by carbohydrates: a mechanism for the "sink regulation" of photosynthesis. The Plant Journal 1993, 3:8I7-828.

39. Foyer CH, Rowell J, Walker D: Measurement of ascorbate content of spinach leaf protoplasts and chloroplasts during illumination. Planta 1983, I 57:239-244.

40. Strohm M, Jouanin L, Kunert KJ, Pruvost C, Polle A, Foyer C, Rennenberg $\mathrm{H}$ : Glutathione synthesis in leaves of transgenic poplar (Populus tremula $\times$ P. alba) overexpressing glutathione synthase. The Plant Journal 1995, 7:|4|-145.

4I. Dietz K-J, Heber U: Light and $\mathrm{CO}_{2}$ limitation of photosynthesis and states of the reactions regenerating ribulose- I,5bisphosphate or reducing 3-phosphoglycerate. Biochimica et Biophysica Acta 1986, 848:392-40I.

42. Kaiser WM, Urbach W: The effect of dihydroxyacetone phosphate and 3-phosphoglycerate on $\mathrm{O}_{2}$ evolution and on the levels of ATP, ADP and $P_{i}$ in isolated intact chloroplasts. Biochimica et Biophysica Acta 1977, 459:337-346.

43. Yemm EW, Willis AJ: The estimation of carbohydrates in plant extracts by anthrone. Biochemical Journal 1954, 57:508-14.

44. Weiler EW: Plant hormone immunoassay based on monoclonal and polyclonal antibodies. In Modern methods of plant analysis Volume 4. Edited by: Linskens HF, Jackson JF. Springer Verlag, Berlin; 1986: I- I7.

45. Miyake C, Shinzaki Y, Miyata M, Tomizawa K-I: Enhancement of cyclic electron flow around PSI at high light its contribution to the induction of non-photochemical quenching of Chl fluorescence in intact leaves of tobacco plants. Plant Cell Physiology 2004, 45: 1426-|433.

46. Kandlbinder A, Finkemeier I, Wormuth D, Hanitzsch M, Dietz K-J: The antioxidant status of photosynthesizing leaves under nutrient deficiency: redox regulation, gene expression and antioxidant activity in Arabidopsis thaliana. Physiologia Plantarum 2004, I 20:62-73.
Publish with Biomed Central and every scientist can read your work free of charge

"BioMed Central will be the most significant development for disseminating the results of biomedical research in our lifetime. "

Sir Paul Nurse, Cancer Research UK

Your research papers will be:

- available free of charge to the entire biomedical community

- peer reviewed and published immediately upon acceptance

- cited in PubMed and archived on PubMed Central

- yours - you keep the copyright
BioMedcentral 